\title{
Evidence for placebo effects on physical but not on biochemical outcome parameters: a review of clinical trials Karin Meissner*, Hans Distel and Ulla Mitzdorf
}

Address: Institute of Medical Psychology, Ludwig-Maximilians-University Munich, Munich, Germany

Email: Karin Meissner* - karin.meissner@med.uni-muenchen.de; Hans Distel - hans.distel@med.uni-muenchen.de; Ulla Mitzdorf - mitzdorf@med.uni-muenchen.de

* Corresponding author

Published: 19 March 2007

BMC Medicine 2007, 5:3 doi:10.|I86/|74|-70|5-5-3

This article is available from: http://www.biomedcentral.com/I74I-70I5/5/3

(C) 2007 Meissner et al; licensee BioMed Central Ltd.

This is an Open Access article distributed under the terms of the Creative Commons Attribution License (http://creativecommons.org/licenses/by/2.0), which permits unrestricted use, distribution, and reproduction in any medium, provided the original work is properly cited.
Received: 5 December 2006

Accepted: 19 March 2007

\begin{abstract}
Background: Recent reviews on placebo effects in clinical trials suggest that objective changes following placebo treatments may not exist or, at least, have been considerably overestimated. However, the possibility that yet unidentified subsets of parameters are responsive to placebo treatments has not been taken into account. Therefore, the aim of the present study is to examine the effects of placebo treatments on objectively measured outcome parameters by specifically focusing on peripheral disease processes.
\end{abstract}

Methods: An initial dataset was collected from a MEDLINE search for placebo-controlled, randomized clinical trials. Trials with stable disease conditions were identified, and the effects of placebo treatments on peripheral outcome parameters were estimated by the changes from baseline in the placebo groups. An explorative data analysis was conducted in order to identify parameter classes with differential responsiveness to placebo treatments. A subgroup meta-analysis of a second dataset was performed to test whether the preliminary classification would also apply to placebo effects derived from the comparison of placebo groups with untreated control groups.

Results: The explorative analysis of outcome parameters and strength of placebo effects yielded a classification into responsive "physical" versus non-responsive "biochemical" parameters. In total, $50 \%$ of trials measuring physical parameters showed significant placebo effects, compared with $6 \%$ of trials measuring biochemical parameters. A subgroup meta-analysis substantiated the differential response (physical parameters: $n=14$, Hedges' pooled effect size $g=0.34,95 \% \mathrm{Cl} 0.22$ to 0.46 ; biochemical parameters: $n=15, g=0.03,95 \% \mathrm{Cl}-0.04$ to 0.10 ). The subanalysis of the second dataset supported the classification and revealed a significant improvement for physical parameters $(n=20, \mathrm{~g}=0.22,95 \% \mathrm{Cl} 0.07$ to 0.36$)$ and a deterioration for biochemical parameters $(n=6, \mathrm{~g}=$ $-0.17,95 \% \mathrm{Cl}-0.31$ to -0.02$)$.

Conclusion: The results suggest that placebo interventions can improve physical disease processes of peripheral organs more easily and effectively than biochemical processes. This differential response offers a good starting point for theoretical considerations on possible mediating mechanisms, and for future investigations in this field. 


\section{Background}

Since the introduction of double-blind randomized controlled trials, which have become the gold standard for assessing the efficacy of pharmacological treatments, reports on marked therapeutic changes in the placebo arms of the trials have led to the widespread belief that placebos have powerful effects [1]. However, in 1997, Kienle and Kiene [2] critically reviewed the placebo literature and concluded that the existing reports on powerful placebo effects do not withstand strong scientific criteria. Instead, most of the reported placebo effects could be explained by factors unrelated to the placebos, such as spontaneous improvement, additional treatment, or statistical regression to the mean. In accordance with other authors, they concluded that the "true" placebo effect [3] could best be identified by comparing the effects in the placebo arm of a study with those in an untreated control arm.

This approach was consequently followed by Hróbjartsson and Gøtzsche in their meta-analysis on clinical placebo effects. They analyzed 114 trials [4], and later an additional 44 trials $[5,6]$, which contained both a placebo arm and a no-treatment control arm. Their analyses confirmed that the overall effect of placebo interventions, when compared with no intervention, is smaller than previously believed. They found a significant placebo effect only for subjective, patient-reported symptoms, most importantly pain. For observer-reported parameters, they did not find statistical evidence for a placebo effect. Slightly different predefinitions, however, do yield a small but significant placebo effect for observer-reported outcomes [7].

One plausible reason for the small or even absent placebo effect in these meta-analyses could be that placebo interventions do not affect all observer-reported outcomes equally. Instead, it might be that only a subset of outcome parameters is responsive to placebo treatment.

The aim of the present study was to examine whether placebo treatment can objectively improve peripheral disease processes. We focused on peripheral disease processes because evidence for placebo effects in this field is rather scarce. Therefore, we analyzed placebo effects on objectively measured outcome parameters from peripheral organs, tissues, and body fluids that were collected from two independent datasets of clinical trials.

The first dataset was derived from a MEDLINE search for placebo-controlled, clinical trials. Because the selected trials did not include untreated control groups, we restricted the dataset to trials on stable disease conditions, from which the effects of placebo treatments could be estimated by baseline changes within the placebo groups. We examined whether placebo treatments had differential effects on parameter subtypes and tried to establish an appropriate parameter classification. To test whether this preliminary classification would also apply to placebo effects derived from the comparison of placebo groups with untreated control groups, we added a subgroup meta-analysis of the trials collected by Hróbjartsson and Gøtzsche [6], using those with peripheral parameters as outcomes.

\section{Methods}

\section{Definition of peripheral outcome parameters}

Peripheral outcome parameters were defined as parameters measuring disease processes in peripheral organs, tissues, and body fluids.

\section{Analysis of placebo effects in clinical trials derived from a MEDLINE search}

Trial identification and selection

The first dataset was derived from a literature search for placebo-controlled clinical trials published in five leading medical journals (Annals of Internal Medicine, British Medical Journal, Journal of the American Medical Association, The Lancet and New England Journal of Medicine) during the decade from 1991 to 2000. For this, a MEDLINE search was conducted by using the search-terms "placebo", "placebo(-)controlled" and "double(-)blind". This resulted in 1723 hits, among them 1689 double-blind, randomized trials using placebo controls. From these, all trials on nonclinical populations were excluded, as well as trials investigating a psychological, neurological or psychiatric disorder, or reporting exclusively on subjective symptoms. Trials lacking a classic placebo control group were also excluded. Furthermore, in order to select only trials with stable disease conditions, trials were excluded when the disease was expected to either improve or deteriorate during the study period, irrespective of experimental treatment, e.g., due to the natural course of the disease, or to co-interventions. For example, mild-to-moderate hypertension would be considered rather stable over a 4-week period in otherwise healthy patients but unstable in women developing hypertension during pregnancy. Similarly, hypercholesterolaemia would be considered rather stable over a 12-week period in patients maintaining their usual diet, but unstable when patients received dietary advice in addition to double-blind treatment. Thus, we searched for trials in which the baseline data provided an appropriate reference to interpret the changes observed within the placebo groups as the effect of the placebo intervention itself and not of other, placebo-unrelated factors. Finally, from the remaining trials, we excluded all trials lacking relevant details to determine the significance of baseline changes within the placebo groups. In total, 34 trials [8-41] investigating chronic stable clinical conditions and reporting on at least one peripheral outcome 
parameter fulfilled all criteria and were included in the analysis (Table 1).

\section{Data extraction}

From the 34 studies meeting the selection criteria, we extracted the baseline changes of peripheral outcome parameters within the placebo groups. When several parameters or time points had been measured, we analyzed the parameter or measurement with the largest effect size during the treatment period because we aimed at identifying outcome parameters most strongly affected by placebo treatment. From studies using a crossover design, we analyzed only the data of the group receiving placebo treatment first to avoid possible unblinding effects and drug carry-over effects.

\section{Data analysis}

For estimating the overall placebo effect on peripheral outcome parameters, we combined the effects of single trials by performing a meta-analysis based on 29 of the 34 trials. In five trials $[10,21,31,36,37]$, data were not sufficient for the meta-analysis as only significance values of the effects of placebo treatment had been reported.

To start our explorative analysis, we determined the significance of the baseline changes within the placebo group of each trial. For this, we used the reported results of statistical testing or, when necessary, the means and measures of variability for performing two-tailed $t$-tests to estimate sig- nificance. We then identified possible common characteristics of parameters with significant or non-significant changes during placebo treatments. To substantiate the resulting dichotomous classification, we performed subgroup meta-analyses of the $n$-weighted standardized mean differences for each parameter subgroup.

In addition, to compare the efficacy of placebo relative to active treatment, we extracted the baseline changes of the analyzed parameters for the active treatment groups as well, and computed their $n$-weighted standardized mean differences. In cases with more than one active treatment arm, we selected the data of the most effective active treatment, according to study results. Placebo efficacy relative to active treatment was then estimated by dividing the standardized mean difference of the effect of placebo treatment by that of the active treatment.

\section{Analysis of placebo effects in clinical trials that included a no-treatment control group}

Trial selection and data extraction

The second dataset for analyzing placebo effects on peripheral outcome parameters was collected from the updated review on placebo effects by Hróbjartsson and Gøtzsche [5,6]. First, we selected all 56 trials with observer-reported continuous outcomes. These included 13 trials with corresponding patient-reported and observer-reported continuous outcomes, from which only the patient-reported outcomes had been included in the

Table I: Reasons for exclusion and number of excluded trials during the selection process of the first dataset

\begin{tabular}{|c|c|}
\hline Reasons for exclusion & $n$ \\
\hline \multicolumn{2}{|l|}{ Lack of placebo-controlled, double-blind, randomized trial } \\
\hline Review, article, or comment & 272 \\
\hline No placebo used & 186 \\
\hline Lack of double-blinding or randomization & 96 \\
\hline \multicolumn{2}{|l|}{ Kind of investigated symptom or condition } \\
\hline No clinical condition & 44 \\
\hline Psychological, neurological or psychiatric condition & 106 \\
\hline Subjective symptom & 67 \\
\hline \multicolumn{2}{|l|}{ No classic placebo control group } \\
\hline Placebo as a dummy to maintain blinding of experimental treatments & 147 \\
\hline Placebo as a control of an add-on treatment & 74 \\
\hline \multicolumn{2}{|l|}{ Lack of stable disease condition } \\
\hline Medical intervention preceding experimental treatment & 120 \\
\hline Co-medication changed during study & 33 \\
\hline Acute condition & 79 \\
\hline Developmental disorder & 20 \\
\hline Trial focus on relapse or prevention & $|3|$ \\
\hline Trial focus on death or other serious events & 113 \\
\hline Trial focus on long-term development of disease & 121 \\
\hline \multicolumn{2}{|l|}{ Miscellaneous } \\
\hline Crossover design and results not separated by sequence & 23 \\
\hline Native physiological parameter not reported & 17 \\
\hline Insufficient detail to estimate placebo effect & 40 \\
\hline Total & 1689 \\
\hline
\end{tabular}


main analysis by Hróbjartsson and Gøtzsche [6]. We excluded all trials on psychological, psychiatric or neurological conditions and those reporting exclusively on subjective symptoms, thereby selecting 26 trials that used peripherally measured parameters as outcomes [42-67]. Because the no-treatment groups controlled for unstable disease conditions due to natural or iatrogenic factors as well as for regression to the mean, this selection, in contrast to the first dataset, also included trials investigating acute or post-surgical conditions [46,47,59-62,67], as well as one trial in which subjects had not had a fully developed disease condition but were selected because of high normal blood pressure values [57], a procedure highly sensitive to the phenomenon of regression to the mean [68].

\section{Data analysis}

The results of the 26 trials were combined by calculating a meta-analysis of the $n$-weighted standardized mean differences for the post-intervention effects in the placebo and no-treatment groups. Subanalyses of parameter subgroups according to our classification were performed identically.

\section{Statistical analysis}

For all meta-analyses, $n$-weighted standardized mean differences and 95\% confidence intervals for the respective placebo effects were calculated using Hedges' adjusted effect size estimation and random effect models. To test for heterogeneity, $\chi^{2}$ and $\mathrm{I}^{2}$ statistics were performed. The computer program RevMan (version 4.2 for Windows) was used to calculate the meta-analysis measures. We allocated positive signs to effects favoring placebo treatment. For all statistical tests, $P<0.05$ (two-tailed) was considered significant.

\section{Results}

\section{Analysis of placebo effects in clinical trials derived from a MEDLINE search}

All 34 placebo-controlled trials [8-41] meeting our inclusion criteria investigated pharmacological treatment, which was administered in 17 different clinical conditions (Additional file 1; Table 2, summarizing the data of the first dataset).

The meta-analysis of the baseline changes within the placebo groups of the 29 trials providing sufficient data showed a significant overall improvement of parameters during placebo treatment (Hedges' pooled effect size $\mathrm{g}=$ $0.21,95 \%$ CI 0.12 to $0.31, P<0.0001$ ) with a high level of heterogeneity between studies $\left(\chi^{2}=63.37, P=0.0001\right.$, $\left.\mathrm{I}^{2}=55.8 \%\right)$.

The explorative analysis revealed that significant placebo effects were predominantly found for parameters measur- ing physical processes, e.g., blood pressure, or forced expiratory volume in 1 second $\left(\mathrm{FEV}_{1}\right)$. Therefore, all types of physical outcome parameters were collected in one class, which was named "physical parameters". The remaining parameters, less frequently responding to placebo treatments, appeared to represent biochemical processes measured in peripheral body fluids and tissues, e.g., cholesterol and cortisol. Therefore, they were all taken together in one alternative class, which was named "biochemical parameters". To be more precise, 8 of 16 trials (50\%) using physical parameters as outcomes reported significant placebo effects compared with only 1 of 18 trials $(6 \%)$ using biochemical parameters. This difference was statistically significant (Fisher's exact probability test, $P<0.01)$.

To further substantiate this classification, we performed subanalyses for both groups of parameters. This revealed a significant placebo effect for physical parameters with a pooled effect size of $\mathrm{g}=0.34$ (95\% CI 0.22 to $0.46, P<$ $0.0001)$, but an effect size close to zero for biochemical parameters ( $\mathrm{g}=0.03,95 \% \mathrm{CI}-0.04$ to $0.10, P=0.41$ ) (see Figure 1). The differentiation between physical and biochemical parameters reduced heterogeneity $\left(\chi^{2}=24.63, P\right.$ $=0.03, \mathrm{I}^{2}=47.2 \%$; and $\chi^{2}=6.39, P=0.96, \mathrm{I}^{2}=0 \%$, respectively). Sensitivity analyses revealed that heterogeneity within the group of physical parameters was due to one outlier [20], and the exclusion of this study substantially reduced heterogeneity $\left(\mathrm{I}^{2}=0 \%\right)$.

All trials of the first dataset provided an active treatment arm. The median placebo efficacy ratio relative to active treatment in the total dataset was 0.26 (interquartile range (IQR) 0.05 to 0.37 ). For the subgroup of physical parameters it was 0.35 (IQR 0.27 to 0.42 ), or about one third of the active treatment effect, whereas for the subgroup of biochemical parameters, the ratio was close to zero $(0.05$; IQR -0.10 to 0.13 ). The difference between placebo efficacy ratios for physical and biochemical parameters was significant (Mann-Whitney $U$ test, $P<0.001$ ).

\section{Analysis of placebo effects in clinical trials that included a no-treatment control group}

The dataset of Hróbjartsson and Gøtzsche [6] provided 26 trials with peripheral parameters as outcomes [42-67] (Additional file 2: Table 3, summarizing the data of the second dataset). In total, pharmacological treatment was investigated in 13 trials, physical treatment in 5, psychological treatment in 5 , and placebo treatment in 3 . These treatments were administered in 12 different disease conditions. The no-treatment control group was provided by a waiting-list control in one trial, and by all patients in seven trials using a crossover design. 


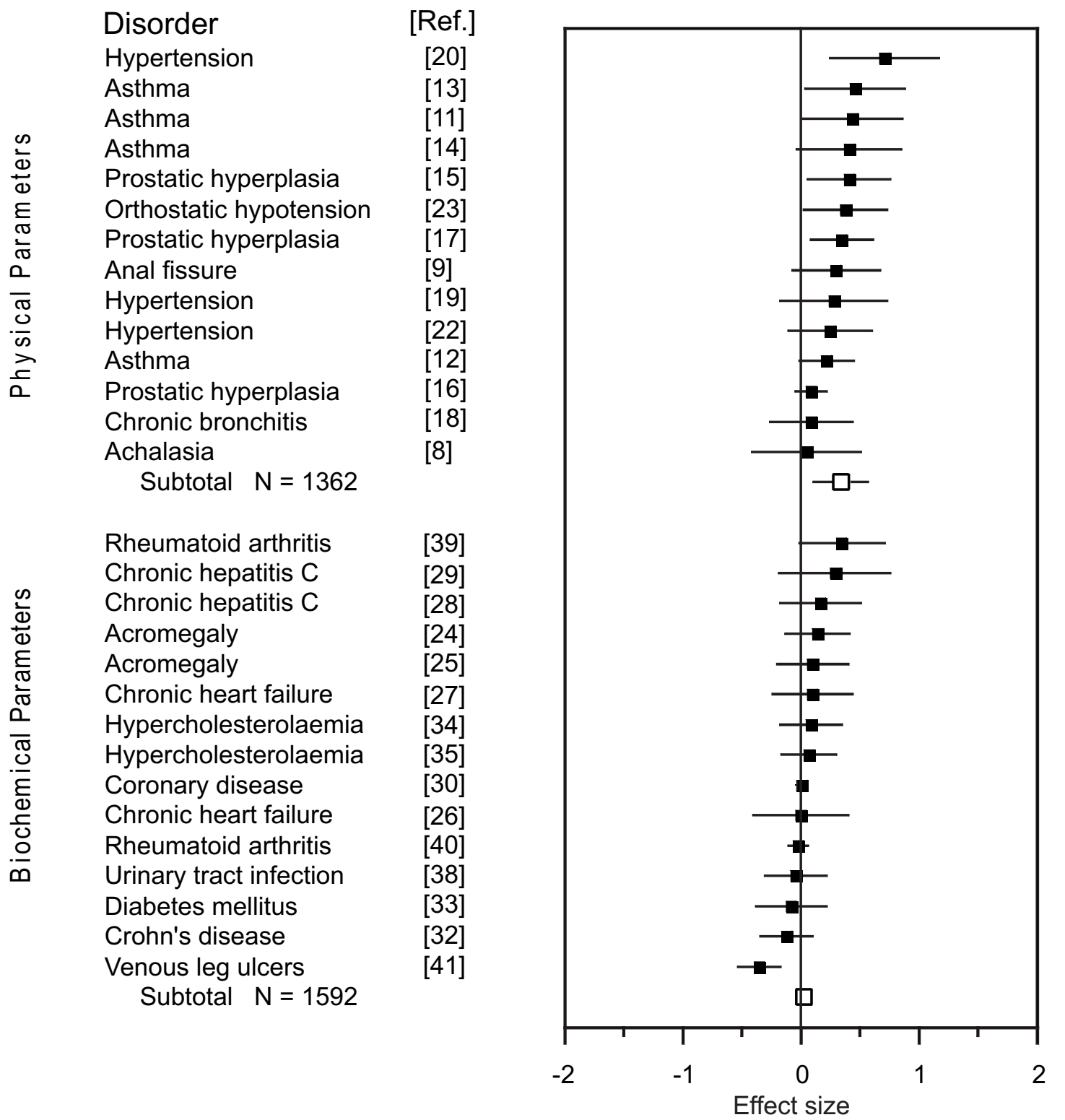

Figure I

Meta-analysis of the first dataset. Standardized mean differences (placebo versus baseline) for physical and biochemical parameters in the 29 trials of the first dataset, retrieved from a MEDLINE search. Black squares indicate single effect sizes, white squares are the subgroups' mean effect sizes, and whiskers the $95 \% \mathrm{Cl}$. Reference numbers are given in square brackets. Positive values favor placebo treatment. 
The meta-analysis of all 26 trials failed to show a significant overall improvement due to placebo treatment ( $\mathrm{g}=$ $0.11,95 \% \mathrm{CI}-0.01$ to $0.24, P=0.08)$, and heterogeneity between studies was high $\left(\chi^{2}=47.24, P=0.005, \mathrm{I}^{2}=\right.$ $47.1 \%)$. The application of our classification showed a significant improvement during placebo treatment for physical parameters $(n=20, \mathrm{~g}=0.22,95 \%$ CI 0.07 to $0.36, P=0.003)$, whereas for biochemical parameters it showed the opposite ( $n=6, \mathrm{~g}=-0.17,95 \%$ CI -0.31 to $0.02, P=0.02$ ) (see Figure 2 ). There was slight heterogeneity within the group of physical parameters $\left(\chi^{2}=30.64\right.$, $\left.P=0.04, \mathrm{I}^{2}=38.0 \%\right)$, but not within the group of biochemical parameters $\left(\chi^{2}=1.36, P=0.93, \mathrm{I}^{2}=0 \%\right)$.

To confirm that the inclusion of acute and post-surgical conditions in our second dataset did not significantly influence the results, a reanalysis with these trials excluded was performed, thereby focusing on stable disease conditions. The effect sizes within the physical and biochemical parameter subgroups remained comparable with that of our main analysis (physical parameters: $n=$ $15, \mathrm{~g}=0.21,95 \%$ CI 0.01 to $0.41, P=0.04$; biochemical parameters: $n=4, \mathrm{~g}=-0.17,95 \% \mathrm{CI}-0.32$ to $-0.01, P=$ $0.03)$.

\section{Discussion}

Our results indicate that placebo interventions can improve objective measures of peripheral disease processes. They furthermore suggest that placebo interventions do not improve all kinds of peripheral outcome parameters equally, but primarily those reflecting physical disease processes.

The meta-analysis of placebo effects in the first dataset (collected from a MEDLINE search for placebo-controlled clinical trials) revealed a significant overall improvement of peripheral outcome parameters by placebo treatments. The explorative analysis indicated that significant effects occurred more frequently on physical than on biochemical parameters. Accordingly, an overall placebo effect across trials was only found within the subgroup of physical parameters. In comparison to the pharmacological medication, the administration of placebos improved physical parameters on average by one-third - a remarkable efficacy, not found for biochemical parameters. These results already suggest that placebo interventions affect physical parameters more frequently and strongly than biochemical parameters.

However, our classification was derived from clinical placebo-controlled trials without a no-treatment arm. These trials had not been designed to analyze placebo effects but to estimate the effect of the active medication against placebo control groups. Therefore, factors not due to placebo treatment may have contributed to the changes in the pla- cebo groups in such trials, e.g., the natural course of the disease, and regression to the mean. We attempted to control for these factors by focusing on trials with otherwise stable disease conditions and tried to minimize the risk of regression to the mean by excluding trials on non-random samples selected by screening from a healthy population [68]. However, even in stable chronic conditions, symptoms may vary over time, and the possibility that some of the improvement on physical parameters may be due to regression cannot be fully excluded by the present data.

Therefore, to further substantiate our classification, we made use of the database of Hróbjartsson and Gøtzsche, which contains a complete collection of trials including both a placebo and a no-treatment control group $[5,6]$. Again, the subanalysis of trials with peripheral outcome parameters revealed a significant improvement from placebos compared with no treatment for the subgroup of physical parameters only. In fact, the analysis even showed a significant negative effect of placebos on biochemical parameters. However, as the number of trials reporting on biochemical parameters was small, this finding should be treated with caution.

A possible limitation in the present study is that physical and biochemical parameters were measured in different trials. Therefore, confounding variables, such as differences in study design or patient characteristics, may have biased the results. However, to use trials in which both parameters are measured in the same condition appears to be problematic, as the outcomes most probably would be coupled, i.e., any physical improvement would be expected to entail changes in biochemical parameters. Hence, our approach to compare trials with either type of parameter may provide the best available evidence to test the appropriateness of our classification. Furthermore, the fact that a remarkable difference in placebo effectiveness between physical and biochemical parameters was found in two different datasets renders the possibility of such a bias quite unlikely.

The responsiveness of physical parameters to placebo treatments becomes plausible when possible mechanisms mediating the effect are considered. Presumably, patients are able to monitor the state of their inner organs by sensory feedback - that is, by visceral perception [69] or by somatic perception (e.g. when experiencing respiratory effort in asthma [70] or ballistic movements in hypertension [71]). They may thus be able to monitor fluctuations in organ states rather quickly. During placebo treatment, the belief of the patient in being treated may result in selective attention to symptom improvement [72]. The momentary experience of symptom improvement may then act as a reward and positively reinforce preceding changes of autonomic function. Thus, visceral learning 


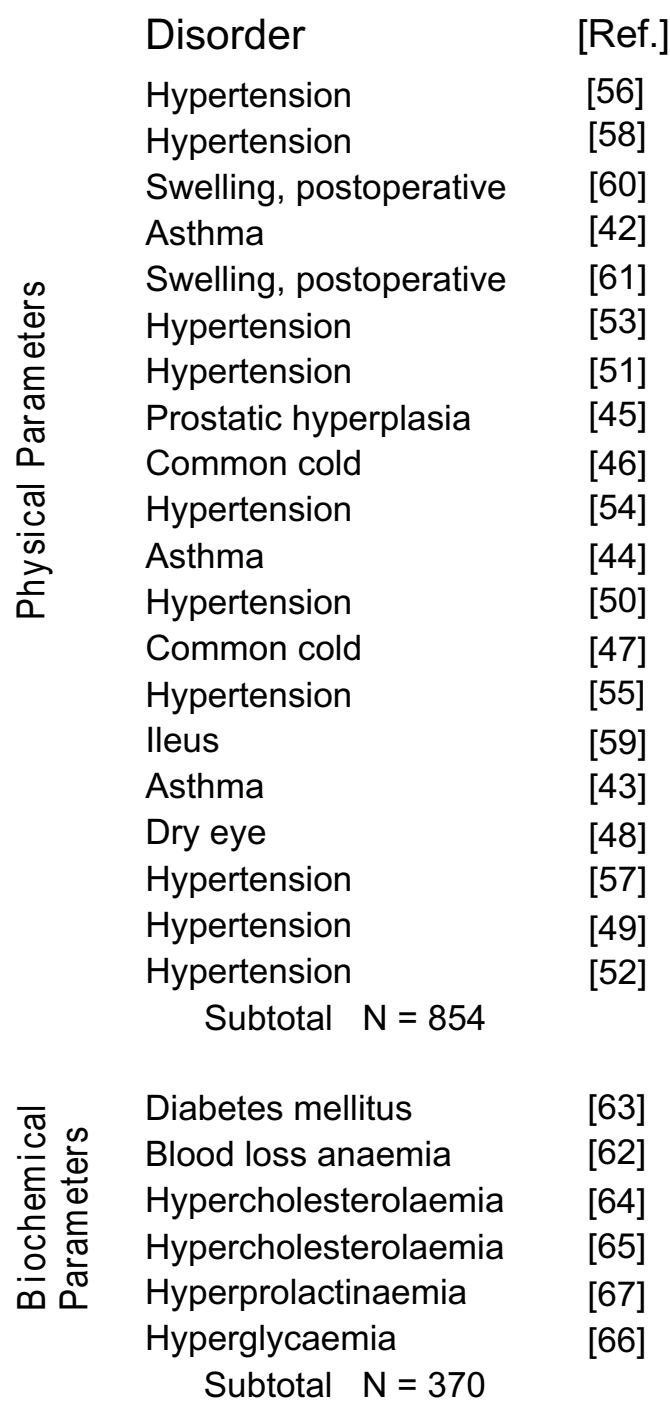

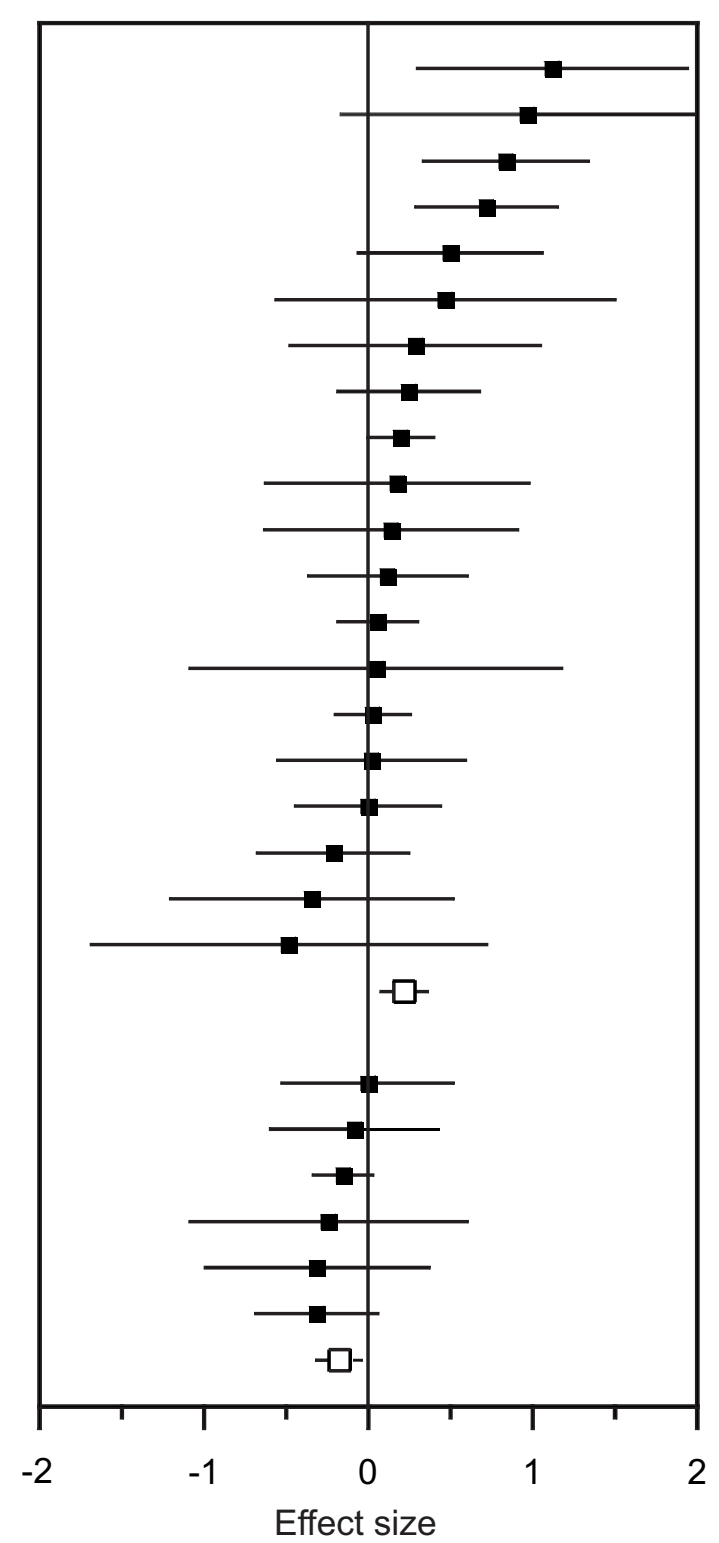

Figure 2

Meta-analysis of the second dataset. Standardized mean differences (placebo versus no treatment) for physical and biochemical parameters in the 26 trials of the second dataset, selected from a published review on placebo effects [6]. For details, see Figure I. 
due to a mechanism similar to operant conditioning [73] may occur, in which the reward is internally provided [74]. The fast neural feedback from inner organs to cortical brain centers, which are involved in autonomic control $[75,76]$, renders physical disease processes ideally suited for this kind of central modification.

Although many of the biochemical parameters are also modulated by the autonomic nervous system, there are several reasons for these being less placebo-sensitive. First, patients may have little or no visceral or somatic sensory feedback to monitor parameter changes, e.g., of insulinlike growth factor-1 or cholesterol, whether spontaneously occurring or induced by treatment. Second, even in cases when the actual concentration of a biochemical parameter can be estimated by the patient (e.g., blood glucose levels [77]) the nonspecific character of the symptoms on which these estimations may be based, and hence the difficulty in identifying spontaneous improvement, may prevent conditioning occurring. For example, varying blood glucose levels may affect thirst, hunger, and mouth dryness [77], symptoms that are also influenced by other factors, most importantly, food and water ingestion. Third, the latency between spontaneous parameter changes and the perception of improvement may be too long to provide contingent feedback [78], e.g., fibrinolytic activity in the healing of venous leg ulcers. Thus, most of the biochemical parameters may lack an essential element for placebo effects to be established, namely, the experience of momentary improvements due to autonomic changes.

A plausible explanation for the deterioration of biochemical parameters in the second dataset might be related to the diet-sensitivity of some of the parameters [63-66]: Patients in placebo groups, believing they are being treated, may become less cautious in following their diet, while untreated patients, necessarily knowing about the lack of treatment, may pay more attention to their diet. Alternatively, an unblinding of placebo recipients during the trial may lead to frustration and therefore to less compliance with the dietary regimen.

One frequently discussed mediating mechanism of placebo effects is the patient's expectation of clinical improvement, which can be raised, for example, by verbal suggestions accompanying placebo treatment $[79,80]$. Expectation and operant conditioning may complement each other. Learning theory emphasizes the importance of response-specific expectations for the performance of operant conditioning tasks [81]. Thus, the patient may direct his/her attention to symptom improvement because he/she is expecting a clinical benefit. In this sense, expectation may be necessary to both initiate and maintain the process of operant conditioning. It has recently been demonstrated that in patients with parkinsonian disease, both the expectation and the actual experience of a clinical benefit during placebo treatment activates the inner-brain reward circuitry $[74,82]$. This experimental result fits well with the hypothesis that both mechanisms (expectation and operant conditioning) are involved in the mediation of placebo effects.

Classical drug conditioning is also considered one of the mechanisms mediating placebo effects $[79,80]$. Classically-conditioned drug effects are, however, expected to extinguish after repeated administration of an inactive agent, and therefore should diminish over the course of clinical trials, in which treatment usually is administered repeatedly [83]. Positive outcomes in the placebo groups of clinical trials are therefore more likely to be induced and maintained by expectation rather than by classical conditioning.

Notably, there is evidence from experimental studies that expectations raised by placebo suggestions can affect physical parameters of peripheral organs, e.g., gastric and pulmonary function [84-86], but not biochemical parameters, i.e., growth hormone and cortisol [87]. These experimental results lend support to the present result that physical and biochemical parameters respond differentially to placebo treatments, with only physical parameters being affected by expectation, and thus displaying placebo effects in clinical trials.

In this study, we were able to identify different kinds of peripheral outcome parameters as one reason for the heterogeneity of placebo effects on observer-reported outcomes. The differential placebo responsiveness of physical versus biochemical parameters should be taken into account when designing future pharmacological studies. A question that ties in with the present results concerns the putative specificity of placebo effects. Depending on the type of disease (e.g., psychiatric, neurological, internal), on the information delivered to the patient, and on the patient's former experiences with treatments, the effects of placebo interventions may differ, and different mechanisms may be involved. To disentangle the specific components of placebo treatments under different circumstances and to work out their effects represents a major challenge for future placebo research.

\section{Conclusion}

Our results indicate that placebo treatments of peripheral disease processes can affect physical parameters more easily and strongly than biochemical parameters. This differentiation holds true for both datasets we tested, i.e., conventional placebo-controlled clinical trials, and clinical trials that included a no-treatment arm. As a corollary, it follows that placebo-responsive subgroups may also be 
identified in datasets in which global averages conceal such specific responses.

Although much progress has been made in the past decade in understanding the biological basis of placebo effects in neurological conditions, e.g., pain and parkinsonian disease, the mechanisms that mediate placebo effects on peripheral organ systems still await to be further elucidated. The differential placebo responsiveness of physical versus biochemical parameters, as disclosed in the present study, offers a good starting point for theoretical considerations on possible mediating mechanisms, as well as for future investigations in this field.

\section{Competing interests}

The authors declare that they have no competing interests.

\section{Authors' contributions}

KM designed the study, collected, prepared and analyzed the data, performed the statistical analysis, interpreted the data and drafted the manuscript. HD and UM participated in the design of the study and in the interpretation of data and helped to draft the manuscript. All authors read and approved the final manuscript.

\section{Additional material}

\section{Additional File 1}

Parameters of trials contributing to the physical and biochemical subgroups of the first dataset (placebo versus baseline)

Click here for file

[http://www.biomedcentral.com/content/supplementary/17417015-5-3-S1.xls]

\section{Additional File 2}

Parameters of trials contributing to the physical and biochemical subgroups of the second dataset (placebo versus no treatment)

Click here for file

[http://www.biomedcentral.com/content/supplementary/17417015-5-3-S2.xls]

\section{Acknowledgements}

KM was supported in part by a grant from the 'Institut für Grenzgebiete der Psychologie und Psychohygiene (IGPP)' at Freiburg (Breisgau), Germany. We gratefully acknowledge Ernst Pöppel for stimulating discussions.

\section{References}

I. Kaptchuk TJ: Powerful placebo: the dark side of the randomised controlled trial. Lancet |998, 35 I: | 722-I725.

2. Kienle GS, Kiene H: The powerful placebo effect: fact or fiction? Clin Epidemiol 1997, 50:1311-1318.

3. Ernst E: Concept of true and perceived placebo effects. $B M J$ 1995, 3 | I:55 I-553.

4. Hrobjartsson A, Gotzsche PC: Is the placebo powerless? An analysis of clinical trials comparing placebo with no treatment. N Engl J Med 200I, 344: I594-I602.

5. Hrobjartsson A, Gotzsche PC: Is the placebo powerless? Update of a systematic review with 52 new randomized trials com- paring placebo with no treatment. I Intern Med 2004, 256:91-100.

6. Hrobjartsson A, Gotzsche PC: Placebo interventions for all clinical conditions. Cochrane Database Syst Rev 2004:CD003974.

7. Meissner K: Preferring patient-reported to observer-reported outcomes substantially influences the results of the updated systematic review on placebos by Hrobjartsson and Gotzsche. J Intern Med 2005, 257:394.

8. Pasricha PJ, Ravich WJ, Hendrix TR, Sostre S, Jones B, Kalloo AN: Intrasphincteric botulinum toxin for the treatment of achalasia. N Engl J Med 1995, 332:774-778.

9. Lund $\mathrm{JN}$, Scholefield $\mathrm{J} \mathrm{H}$ : A randomised, prospective, doubleblind, placebo-controlled trial of glyceryl trinitrate ointment in treatment of anal fissure. Lancet 1997, 349: I I-14.

I0. D'Alonzo GE, Nathan RA, Henochowicz S, Morris RJ, Ratner P, Rennard SI: Salmeterol xinafoate as maintenance therapy compared with albuterol in patients with asthma. Jama 1994, 27I:|4|2-|4|6.

II. Israel E, Rubin P, Kemp JP, Grossman J, Pierson W, Siegel SC, Tinkelman D, Murray JJ, Busse W, Segal AT, Fish J, Kaiser HB, Ledford D, Wenzel S, Rosenthal R, Cohn J, Lanni C, Pearlman H, Karahalios P, Drazen JM: The effect of inhibition of 5-lipoxygenase by zileuton in mild-to-moderate asthma. Ann Intern Med 1993, I 1 9:1059-1066.

12. Knorr B, Matz J, Bernstein JA, Nguyen H, Seidenberg BC, Reiss TF, Becker A: Montelukast for chronic asthma in 6- to 14-year-old children: a randomized, double-blind trial. Pediatric Montelukast Study Group. Jama 1998, 279: | I8I-I I86.

13. Leff JA, Busse WW, Pearlman D, Bronsky EA, Kemp J, Hendeles L, Dockhorn R, Kundu S, Zhang J, Seidenberg BC, Reiss TF: Montelukast, a leukotriene-receptor antagonist, for the treatment of mild asthma and exercise-induced bronchoconstriction. $N$ Engl J Med 1998, 339: I47-I52.

14. Tamaoki J, Kondo M, Sakai N, Aoshiba K, Tagaya E, Nakata J, Isono K, Nagai A: Effect of suplatast tosilate, a Th2 cytokine inhibitor, on steroid-dependent asthma: a double-blind randomised study. Tokyo Joshi-Idai Asthma Research Group. Lancet 2000, 356:273-278.

15. Berges RR, Windeler J, Trampisch HJ, Senge T: Randomised, placebo-controlled, double-blind clinical trial of beta-sitosterol in patients with benign prostatic hyperplasia. Beta-sitosterol Study Group. Lancet 1995, 345: I529-1532.

16. Gormley GJ, Stoner E, Bruskewitz RC, Imperato-McGinley J, Walsh PC, McConnell JD, Andriole GL, Geller J, Bracken BR, Tenover JS, Vaughan ED, Pappas F, Taylor A, Binkowitz B, Jennifer NG: The effect of finasteride in men with benign prostatic hyperplasia. The Finasteride Study Group. N Engl J Med 1992, 327:1185-1191.

17. Lepor H, Williford WO, Barry MJ, Brawer MK, Dixon CM, Gormley G, Haakenson C, Machi M, Narayan P, Padley RJ: The efficacy of terazosin, finasteride, or both in benign prostatic hyperplasia. Veterans Affairs Cooperative Studies Benign Prostatic Hyperplasia Study Group. N Engl J Med 1996, 335:533-539.

18. Anzueto A, Jubran A, Ohar JA, Piquette CA, Rennard SI, Colice G, Pattishall EN, Barrett J, Engle M, Perret KA, Rubin BK: Effects of aerosolized surfactant in patients with stable chronic bronchitis: a prospective randomized controlled trial. Jama 1997, 278:|426-|43|.

19. Duffy SJ, Gokce N, Holbrook M, Huang A, Frei B, Keaney JF Jr, Vita JA: Treatment of hypertension with ascorbic acid. Lancet 1999, 354:2048-2049.

20. Materson BJ, Reda DJ, Cushman WC, Massie BM, Freis ED, Kochar MS, Hamburger RJ, Fye C, Lakshman R, Gottdiener J, Ramirez EA, Henderson WG: Single-drug therapy for hypertension in men. A comparison of six antihypertensive agents with placebo. The Department of Veterans Affairs Cooperative Study Group on Antihypertensive Agents. N Engl J Med 1993, 328:9|4-92।.

21. Siegel D, Hulley SB, Black DM, Cheitlin MD, Sebastian A, Seeley DG, Hearst N, Fine R: Diuretics, serum and intracellular electrolyte levels, and ventricular arrhythmias in hypertensive men. Jama 1992, 267: 1083-1089.

22. Toft I, Bonaa KH, Ingebretsen OC, Nordoy A, Jenssen T: Effects of n-3 polyunsaturated fatty acids on glucose homeostasis and blood pressure in essential hypertension. A randomized, controlled trial. Ann Intern Med 1995, I23:91 I-918. 
23. Low PA, Gilden JL, Freeman R, Sheng KN, McElligott MA: Efficacy of midodrine vs placebo in neurogenic orthostatic hypotension. A randomized, double-blind multicenter study. Midodrine Study Group. Jama I997, 277: I046-I05I.

24. Ezzat S, Snyder PJ, Young WF, Boyajy LD, Newman C, Klibanski A, Molitch ME, Boyd AE, Sheeler L, Cook DM, Malarkey WB, Jackson I, Vance ML, Thorner MO, Barkan A, Frohman LA, Melmed S: Octreotide treatment of acromegaly. A randomized, multicenter study. Ann Intern Med 1992, I I 7:7 I 1-7I8.

25. Trainer PJ, Drake WM, Katznelson L, Freda PU, Herman-Bonert V, van der Lely AJ, Dimaraki EV, Stewart PM, Friend KE, Vance ML, Besser GM, Scarlett JA: Treatment of acromegaly with the growth hormone-receptor antagonist pegvisomant. $N$ Engl J Med 2000, 342:1171-1177.

26. Kiowski W, Sutsch G, Hunziker P, Muller P, Kim J, Oechslin E, Schmitt $\mathrm{R}$, Jones R, Bertel $\mathrm{O}$ : Evidence for endothelin-I-mediated vasoconstriction in severe chronic heart failure. Lancet 1995, 346:732-736.

27. Khatta M, Alexander BS, Krichten CM, Fisher ML, Freudenberger R, Robinson SW, Gottlieb SS: The effect of coenzyme QIO in patients with congestive heart failure. Ann Intern Med 2000, I 32:636-640.

28. Di Bisceglie AM, Conjeevaram HS, Fried MW, Sallie R, Park Y, Yurdaydin C, Swain M, Kleiner DE, Mahaney K, Hoofnagle JH: Ribavirin as therapy for chronic hepatitis C. A randomized, doubleblind, placebo-controlled trial. Ann Intern Med 1995, I 23:897-903.

29. Shindo M, Di Bisceglie AM, Cheung L, Shih JW, Cristiano K, Feinstone $\mathrm{SM}$, Hoofnagle JH: Decrease in serum hepatitis $C$ viral RNA during alpha-interferon therapy for chronic hepatitis $\mathbf{C}$. Ann Intern Med I99I, I I 5:700-704.

30. Stephens NG, Parsons A, Schofield PM, Kelly F, Cheeseman K, Mitchinson MJ: Randomised controlled trial of vitamin $E$ in patients with coronary disease: Cambridge Heart Antioxidant Study (CHAOS). Lancet 1996, 347:78I-786.

31. Greenberg GR, Feagan BG, Martin F, Sutherland LR, Thomson AB, Williams CN, Nilsson LG, Persson T: Oral budesonide for active Crohn's disease. Canadian Inflammatory Bowel Disease Study Group. N Engl J Med I994, 33 I:836-84 I.

32. Targan SR, Hanauer SB, van Deventer SJ, Mayer L, Present DH, Braak man T, DeWoody KL, Schaible TF, Rutgeerts PJ: A short-term study of chimeric monoclonal antibody CA2 to tumor necrosis factor alpha for Crohn's disease. Crohn's Disease cA2 Study Group. N Engl J Med 1997, 337:1029-I035.

33. Acerini CL, Patton CM, Savage MO, Kernell A, Westphal O, Dunger $\mathrm{DB}$ : Randomised placebo-controlled trial of human recombinant insulin-like growth factor I plus intensive insulin therapy in adolescents with insulin-dependent diabetes mellitus. Lancet 1997, 350:1199-1204.

34. Betteridge DJ, Bhatnager D, Bing RF, Durrington PN, Evans GR, Flax $H$, Jay RH, Lewis-Barned N, Mann J, Matthews DR, Miller JP, Reckless JPD, Sturley R, Taylor KG, Winder AF: Treatment of familial hypercholesterolaemia. United Kingdom lipid clinics study of pravastatin and cholestyramine. Bmj I992, 304: I335-I338.

35. Miettinen TA, Puska P, Gylling H, Vanhanen H, Vartiainen E: Reduction of serum cholesterol with sitostanol-ester margarine in a mildly hypercholesterolemic population. N EnglJ Med I995, 333: $1308-13 \mid 2$

36. Sattar N, Perera M, Small M, Lumsden MA: Hormone replacement therapy and sensitive $C$-reactive protein concentrations in women with type-2 diabetes. Lancet 1999, 354:487-488.

37. Silverberg SJ, Bone HG 3rd, Marriott TB, Locker FG, Thys-Jacobs S, Dziem G, Kaatz S, Sanguinetti EL, Bilezikian JP: Short-term inhibition of parathyroid hormone secretion by a calcium-receptor agonist in patients with primary hyperparathyroidism. $N$ Engl J Med 1997, 337:1506-1510.

38. Raz R, Stamm WE: A controlled trial of intravaginal estriol in postmenopausal women with recurrent urinary tract infections. N Engl J Med 1993, 329:753-756.

39. Clark P, Casas E, Tugwell P, Medina C, Gheno C, Tenorio G, Orozco JA: Hydroxychloroquine compared with placebo in rheumatoid arthritis. A randomized controlled trial. Ann Intern Med 1993, I 19:1067-1071.

40. Simon LS, Weaver AL, Graham DY, Kivitz AJ, Lipsky PE, Hubbard RC, Isakson PC, Verburg KM, Yu SS, Zhao WW, Geis GS: Anti-inflammatory and upper gastrointestinal effects of celecoxib in rheumatoid arthritis: a randomized controlled trial. Jama 1999, 282:1921-1928.

41. Herouy Y, Hellstern MO, Vanscheidt W, Schopf E, Norgauer J: Factor XIII-mediated inhibition of fibrinolysis and venous leg ulcers. Lancet 2000, 355:1970-1971.

42. Godfrey S, Silverman M: Demonstration by placebo response in asthma by means of exercise testing. I Psychosom Res 1973, I 7:293-297.

43. May O, Hansen NC: Comparison of terbutaline, isotonic saline, ambient air and non-treatment in patients with reversible chronic airway obstruction. Eur Respir J 1988, I:527-530.

44. Morton AR, Fazio SM, Miller D: Efficacy of laser-acupuncture in the prevention of exercise-induced asthma. Ann Allergy 1993, 70:295-298.

45. Nawrocki JD, Bell T], Lawrence WT, Ward JP: A randomized controlled trial of transurethral microwave thermotherapy. $\mathrm{Br} J$ Urol 1997, 79:389-393.

46. Diamond L, Dockhorn RJ, Grossman J, Kisicki JC, Posner M, Zinny MA, Koker P, Korts D, Wecker MT: A dose-response study of the efficacy and safety of ipratropium bromide nasal spray in the treatment of the common cold. J Allergy Clin Immunol 1995 95:II39-II46.

47. Hayden FG, Diamond L, Wood PB, Korts DC, Wecker MT: Effectiveness and safety of intranasal ipratropium bromide in common colds. A randomized, double-blind, placebo-controlled trial. Ann Intern Med 1996, I 25:89-97.

48. Blades KJ, Patel S, Aidoo KE: Oral antioxidant therapy for marginal dry eye. Eur J Clin Nutr 200I, 55:589-597.

49. Antivalle M, Lattuada S, Salvaggio A, Paravicini M, Rindi M, Libretti A Placebo effect and adaptation to noninvasive monitoring of BP. J Hum Hypertens 1990, 4:633-637.

50. Asmar R, Boutelant S, Chaignon M, Guedon J, Topouchian J, Mallion JM, Safar M: Repeated measurements of non-invasive ambulatory blood pressure: distinction between reproducibility and the proper effect of placebo. Blood Press Monit 1996, I:283-288.

5I. Bosley F, Allen TW: Stress management training for hypertensives: cognitive and physiological effects. J Behav Med 1989, 12:77-89.

52. Canino E, Cardona R, Monsalve P, Perez Acuna F, Lopez B, Fragachan $\mathrm{F}$ : A behavioral treatment program as a therapy in the control of primary hypertension. Acta Cient Venez 1994, 45:23-30.

53. Frankel BL, Patel DJ, Horwitz D, Friedewald WT, Gaarder KR Treatment of hypertension with biofeedback and relaxation techniques. Psychosom Med 1978, 40:276-293.

54. Hossmann V, FitzGerald GA, Dollery CT: Influence of hospitalization and placebo therapy on blood pressure and sympathetic function in essential hypertension. Hypertension 1981, 3: II3-118.

55. Rossi A, Ziacchi $V$, Lomanto $B$ : The hypotensive effect of a single daily dose of labetalol: a preliminary study. Int J Clin Pharmacol Ther Toxicol 1 982, 20:438-445.

56. Seer $P$, Raeburn JM: Meditation training and essential hypertension: a methodological study. I Behav Med |980, 3:59-7|

57. Sinaiko AR, Gomez-Marin O, Prineas RJ: Effect of low sodium diet or potassium supplementation on adolescent blood pressure. Hypertension 1993, 21:989-994.

58. Yates RG, Lamping DL, Abram NL, Wright C: Effects of chiropractic treatment on blood pressure and anxiety: a randomized, controlled trial. J Manipulative Physiol Ther 1988, I I:484-488.

59. GRECHO: Evaluation of 2 homeopathic products on the resumption of transit after digestive surgery. A multicenter controlled trial. Presse Med 1989, 18:59-62

60. Hashish BI, Harvey W, Harris M: Anti-inflammatory effects of ultrasound therapy: evidence for a major placebo effect. British Journal of Rheumatology 1986, 25:77-8I.

6I. Hashish I, Hai HK, Harvey W, Feinmann C, Harris M: Reduction of postoperative pain and swelling by ultrasound treatment: a placebo effect. Pain 1988, 33:303-3I I.

62. Crosby L, Palarski VA, Cottington E, Cmolik B: Iron supplementation for acute blood loss anemia after coronary artery bypass surgery: a randomized, placebo-controlled study. Heart Lung 1994, 23:493-499.

63. Anderson BJ, Brackett J, Ho J, Laffel LM: An intervention to promote family teamwork in diabetes management tasks: relationships among parental involvement, adherence to blood glucose monitoring, and glycemic control in young adoles- 
cents with type I diabetes. In Promoting adherence to medical treatment in chronic childhood illness: concepts, methods and interventions Mahwah: Lawrence Erlbaum Associates; 2000:347-365.

64. Lindholm LH, Ekbom T, Dash C, Isacsson A, Schersten B: Changes in cardiovascular risk factors by combined pharmacological and nonpharmacological strategies: the main results of the CELL Study. J Intern Med 1996, 240: I3-22.

65. Tuomilehto J, Voutilainen E, Huttunen J, Vinni S, Homan K: Effect of guar gum on body weight and serum lipids in hypercholesterolemic females. Acta Med Scand 1980, 208:45-48.

66. Karunakaran S, Hammersley MS, Morris RJ, Turner RC, Holman RR: The Fasting Hyperglycaemia Study: III. Randomized controlled trial of sulfonylurea therapy in subjects with increased but not diabetic fasting plasma glucose. Metabolism 1997, 46:56-60.

67. Andersen NA, Damm P, Tabor A, Pedersen IM, Harring M: Prevention of breast pain and milk secretion with bromocriptine after second-trimester abortion. Acta Obstet Gynecol Scand 1990, 69:235-238.

68. Davis CE: The effect of regression to the mean in epidemiologic and clinical studies. Am J Epidemiol 1976, I04:493-498.

69. Jones GE: Perception of visceral sensations: a review of recent findings, methodologies, and future directions. In Advances in psychophysiology Volume 5. Edited by: Jennings JR, Ackles PK, Coles MGH. London: Kingsley; 1994:55-I9l.

70. Manning HL, Schwartzstein RM: Respiratory sensations in asthma: physiological and clinical implications. J Asthma 200I, 38:447-460.

7I. O'Brien WH, Reid GJ, Jones KR: Differences in heartbeat awareness among males with higher and lower levels of systolic blood pressure. Int ] Psychophysiol 1998, 29:53-63.

72. Allan LG, Siegel S: A signal detection theory analysis of the placebo effect. Eval Health Prof 2002, 25:410-420.

73. Miller NE: Learning of visceral and glandular responses. Science 1969, 163:434-445.

74. de la Fuente-Fernandez R, Schulzer M, Stoessl AJ: Placebo mechanisms and reward circuitry: clues from Parkinson's disease. Biol Psychiatry 2004, 56:67-7I.

75. Cechetto DF, Saper CB: Evidence for a viscerotopic sensory representation in the cortex and thalamus in the rat. J Comp Neurol 1987, 262:27-45.

76. Cechetto DF: Role of the cerebral cortex in autonomic function. In Central Regulation of Autonomic Functions Edited by: Loewy AD, Spyer KM. Oxford, UK: Oxford University Press; 1990:208-223.

77. Schandry R, Leopold C, Vogt M: Symptom reporting in asthma patients and insulin-dependent diabetics. Biol Psychol 1996, 42:23I-244.

78. Wagner $\mathrm{K}$, Neuringer $\mathrm{A}$ : Operant variability when reinforcement is delayed. Learn Behav 2006, 34: $111-123$.

79. Klosterhalfen S, Enck P: Psychobiology of the placebo response. Auton Neurosci 2006, I 25:94-99.

80. Benedetti F, Mayberg HS, Wager TD, Stohler CS, Zubieta JK: Neurobiological mechanisms of the placebo effect. J Neurosci 2005 , 25:10390-10402.

8I. Watanabe M, Cromwell HC, Tremblay L, Hollerman JR, Hikosaka K, Schultz W: Behavioral reactions reflecting differential reward expectations in monkeys. Exp Brain Res 2001, 140:5 I I-5 I8.

82. de La Fuente-Fernandez R, Stoessl AJ: The biochemical bases for reward. Implications for the placebo effect. Eval Health Prof 2002, 25:387-398

83. Kirsch I: The placebo effect as a conditioned response: failures of the "litmus test". Behavioral and Brain Sciences |99|, 14:200-204.

84. Levine ME, Stern RM, Koch KL: The effects of manipulating expectations through placebo and nocebo administration on gastric tachyarrhythmia and motion-induced nausea. Psychosom Med 2006, 68:478-486.

85. Meissner K, Gluender H, Mitzdorf U: Placebo effects on gastric slow wave frequency [abstract]. Psychophysiology 2005, 42:SI5-SI6.

86. Leigh R, MacQueen G, Tougas G, Hargreave FE, Bienenstock J: Change in forced expiratory volume in I second after sham bronchoconstrictor in suggestible but not suggestion-resistant asthmatic subjects: a pilot study. Psychosom Med 2003, 65:79|-795.
87. Benedetti F, Pollo A, Lopiano L, Lanotte M, Vighetti S, Rainero I: Conscious expectation and unconscious conditioning in analgesic, motor, and hormonal placebo/nocebo responses. J Neurosci 2003, 23:43I5-4323.

\section{Pre-publication history}

The pre-publication history for this paper can be accessed here:

http://www.biomedcentral.com/1741-7015/5/3/prepub
Publish with Biomed Central and every scientist can read your work free of charge

"BioMed Central will be the most significant development for disseminating the results of biomedical research in our lifetime. "

Sir Paul Nurse, Cancer Research UK

Your research papers will be:

- available free of charge to the entire biomedical community

- peer reviewed and published immediately upon acceptance

- cited in PubMed and archived on PubMed Central

- yours - you keep the copyright

Submit your manuscript here:

http://www.biomedcentral.com/info/publishing_adv.asp
BioMedcentral 